\section{Pneumothorax after fine needle aspiration of the breast}

SIR, - We are not surprised by Mr C A Gateley and colleagues' report of pneumothorax as a complication of fine needle aspiration of the breast.' We note that the authors are unaware of previous reports of this complication. In fact, the incidence of this complication was reported as $0 \cdot 18 \%$ in a large Italian series of 74000 fine needle aspirations of the breast, ${ }^{2}$ and there have been several isolated case reports. $^{3+}$

Seven months ago we unsuccessfully submitted to the $B M F$ a report describing this complication in a young thin woman referred to the accident and emergency department in the evening by her general practitioner. She had complained of pleuritic chest pain and dyspnoea since fine needle aspiration of a benign breast lesion at the surgical outpatient department earlier that day.

We agree with $\mathrm{Mr}$ Gateley and colleagues that workers other than those actually performing the procedure must be aware of the hazards, however rare. This is particularly true for general practitioners and those working in accident and emergency departments, who may be presented with this delayed complication after the outpatient clinics are closed and those working in them have long gone home.

JAMES STEVENSON ANDREW S JAMES MICHAEL A JOHNSTON IAIN W R ANDERSON

Accident and Emergency Department,

Victoria Infirmary,

Glasgow G42 9TY

1 Gateley CA, Maddox PR, Mansel RE. Pneumothorax: a complication of fine needle aspiration of the breast. BMF 1991;303 627-8. (14 September.)

2 Catania S, Boccato P, Bono A, Di Pietro S, Pilotti S, Ciatto S, $e$ al. Pneumothorax: a rare complication of fine needle aspiration of the breast. Acta Cytol 1989;33:140.

3 Ariso R, Carbone G, Maina A, Donovito V. Pneumothorax as complication of fine needle aspiration of the breast. Panminerva Med 1988;30:58-9.

4 Orr KB, Megarey CY. Pneumothorax after aspiration of breas cysts. Med J Aust 1978;1:101.

SIR,-Mr C A Gately and colleagues reported the interesting but rare complication of pneumothorax after fine needle aspiration of the breast as if this was new information. ${ }^{1}$ They even state that to the best of their knowledge it has not been reported previously, but this is simply not correct. The first report (of three cases) was in $1978,,^{2}$ and a further single case was reported in $1990 .^{3}$ This lack of a review of published work so that the authors appear as the first to unveil new information is surely not acceptable when a paper is offered to any major journal.

I am glad, however, that we came to the same conclusion: that if the aspirating needle is held tangentially to the chest wall during the procedure the pleura cannot be punctured by either the clinician or the patient.

LAURENCE H STEWART

Department of Urology

Belfast BT97AB

1 Gately CA, Maddox PR, Mansel RE. Pneumothorax: a complication of fine needle aspiration of the breast. $B M 7$ 1991:303: tion of fine needle asp

2 Orr KB, Megarey CJ. Pneumothorax after aspiration of breas cysts. Med $\mathcal{F}$ Aust $1978 ;$;i: 101.

3 Stewart LH. Pneumothorax following breast aspiration. Ulster Med f 1990;59:211-2.

SIR, - I have two comments to make regarding $\mathrm{Mr}$ C A Gateley and colleagues' short report on pneumothorax as a complication of fine needle aspiration of the breast.

In their study most of the doctors who performed breast aspirations that were complicated by pneumothorax were registrars; only one pneumothorax occurred after aspiration by a consultant. It has been our practice for the past eight years to restrict fine needle aspiration to designated aspirators (two consultants and one research registrar). Of roughly 8000 aspirations that were done during this interval, over $90 \%$ were done by these designated staff. During this period three penumothoraces occurred, two after aspiration by non-designated aspirators and one after aspiration by a designated aspirator. It seems that not only are experienced aspirators more likely to obtain a diagnostic aspirate ${ }^{23}$ but they are less likely to cause a pneumothorax.

I disagree with the method described for performing fine needle aspiration cytology of lesions in the upper outer quadrant of the breast. If the lesion to be aspirated is firmly fixed between the index and middle fingers of the left hand then the fingers are driven down into the intercostal space and the lesion is moved directly over a rib. With this method one can insert the needle through the skin directly overlying the lesion, which I am certain increases the likelihood of hitting the lesion and obtaining a representative aspirate; one may occasionally hit the rib but it is almost impossible to puncture pleura.

J MICHAEL DIXON

Department of Surgery,

Royal Infirmary

Edinburgh EH3,

1 Gateley CA, Maddox PR, Mansel RE. Pneumothorax: complication of fine needle aspiration of the breast. $B M \mathcal{Y}$ 1991;303:627-8. (14 September.)

2 Dixon JM, Lamb J, Anderson TJ. Fine needle aspiration of the breast: the importance of the aspirator. Lancet 1983;ii:564.

3 Barrows GM, Anderson TJ, Lamb J, Dixon JM. Fine needle aspiration of breast cancer: relationship of clinical factors o cytology results in 689 primary malignancies. Cancer 1986;58:1493-8

\section{Blood pressure and myocardial infarction}

SIR, - A surprising aspect of the debate on the J or $\mathrm{U}$ shaped curve is the apparent failure to recognise that when perfusion pressure is reduced blood viscosity will increase commensurate with the reduction in the rate of blood flow

Dr Ralph B D'Agostino and colleagues noted that "Our data shed no light on the actual mechanism of the U curve," although they seemed to recognise that a problem of blood flow was involved by suggesting that "patients with severe coronary heart disease may be vulnerable to low perfusion pressures." There is ample evidence that a combination of increased blood viscosity and reduced perfusion pressure may have fatal consequences.

Letcher et al showed that there was a direct relation between blood viscosity and blood pressure ${ }^{2}$ confirming a number of early reports. From this aspect the raised blood pressure can be interpreted as a physiological response to the increased peripheral resistance offered by the hyperviscous blood. Subjects with hypertension related to viscosity treated with antihypertensive agents would be at risk of having perfusion pressure reduced to a level below that required to maintain peripheral blood flow.

Dr D'Agostino and colleagues emphasised, however, that the $\mathrm{U}$ curve relation was found only in subjects with myocardial infarction. Chien concluded that abnormal blood rheology played a pathophysiological role in both hypertension and myocardial infarction. ${ }^{3}$ The $U$ curve for blood pressure may be linked to myocardial infarction through the effect of a partial occlusion on blood flow distal to the occlusion in coronary arteries. Partial vascular occlusion reduces the rate of blood flow distal to the occlusion commensurate with the degree of occlusion, and the reduction in flow rate results in an increase in blood viscosity. Therefore the greater the reduction in patency the greater the viscosity of distal blood. In hypertensive states the rate of flow through semipatient vessels may be sufficient to maintain distal blood flow, but the therapeutic reduction of blood pressure could result in the loss of perfusion pressure sufficient to maintain distal blood flow.

The ascending limb of the $U$ curve of $\mathrm{Dr}$ D'Agostino and colleagues can be interpreted as a demonstration of the anticipated response to antihypertensive treatment of subjects with partly occluded coronary arteries, raised blood viscosity, and hypertension. Those subjects contributing to the lowest point of the curve $(75-79 \mathrm{~mm} \mathrm{Hg}$ ) would have either the most viscous blood or the least patent vessels. With the progressive reduction in diastolic pressure, increasing numbers of subjects would have perfusion pressures that were inadequate to overcome the combined effects of high blood viscosity and poorly patent coronary vessels.

In practical terms this concept provides a basis for treating at least some patients with hypertension (for example, those with increased blood viscosity) as haemorheological problems. Treatment would be based on agents such as fish oil rich in (1) 3 fatty acids or oxpentifylline, both of which have been shown to have haemorheological benefits. The use of a vegetarian diet to lower blood pressure by the group in Perth, Australia, ${ }^{+5}$ was based on information that showed that vegetarians have low blood pressure, low blood viscosity, and a low incidence of coronary heart disease.

If the mortality associated with lowering blood pressure in subjects with myocardial infarction is to be reduced it seems essential to measure blood viscosity before deciding on the most appropriate means of reducing blood pressure.

L O SIMPSON

\section{Department of General Practice,}

Medical School,

University of Otago,

Dunedin, New Zealand

1 D'Agostino RB, Belanger AJ, Kannel WB, Cruickshank JM. Relation of low diastolic blood pressure to coronary heart
disease death in presence of myocardial infarction: the Framdisease death in presence of myocardial infarction: ingham study. $B M 7$ 1991;303:385-9. (17 August.)

2 Letcher RL, Chien S, Pickering TG, Sealey JE, Laragh JH. Direct relationship between blood pressure and blood viscosity in normal and hypertensive subjects: role of fibrinogen and concentration. Am F Med 1981;70:1195-202.

3 Chien S. Blood rheology in myocardial infarction and hypertension. Biorheology 1986;23:633-53.

4 Margetts BM, Beilin LJ, Vandongen R, Armstrong BK. Vegetarian diet in mild hypertension: a randomised controlled trial. $B M \mathcal{B} 1986 ; 293: 1468-71$.

5 Beilin LJ, Armstrong BK, Margetts BM, Rouse IL, Vandongen

R. Vegetarian diet and blood pressure. Nephron 1987;47 (suppl

1): $37-41$.

\section{Improving survival after large bowel cancer}

SIR, - Mr T G Allen-Mersh's editorial on surgical resection of hepatic metastases from colorectal cancer raises several important points. ${ }^{\prime}$ The unexpected finding of hepatic metastasis at operation for apparently resectable primary disease should no longer be regarded as an open and shut case. $\mathrm{Mr}$ Allen-Mersh comments, however, that survival after resection of lesions detected by intraoperative ultrasonography "may be better" than that after resection of larger tumours detectable by conventional means. Even if this had been shown by an appropriate trial any difference is more likely to arise from lead time bias, estimated to be of the order of 16 months. ${ }^{12}$ A $4 \mathrm{~mm}$ deposit (at the limit of detection of this technique) contains $10^{8}$ cells which have had one to two years to metastasise, so it is likely that no increase in cures will be seen.

The rationale behind improving cure rates by gaining regional control of metastases is not new. Halstead and his successors explored increasingly radical chest and lymph node resections to prevent systemic metastasis from breast cancer. It is now 